\title{
Beneficios do resveratrol como ativo cosmético na prevenção do envelhecimento cutâneo
}

\author{
Benefits of resveratrol as an active component in the prevention \\ of skin aging
} Recebido em: 19/03/2020
Aceito em: $23 / 06 / 2020$

Andreia Medeiros PALADINI; Talita Durante LOPES;

Karina Elisa MACHADO

Universidade do Vale do Itajaí- UNIVALI. Rodovia SC-401, 5025,

Saco Grande, CEP 88032-005. Florianópolis, SC, Brasil.

E-mail:karymachado@hotmail.com

\section{ABSTRACT}

The improvement of the health parameters of the population is one of the most outstanding achievements of humankind, and this achievement has become a challenge for today. Living more is important as long as we can add quality of life, physical and mental, for the years we have won, and therefore the search for resources that can help us achieve this goal has stimulated new research and among these, of active ingredients to be used in cosmetic formulations that can combat skin aging. The aging of the skin may be intrinsic, meaning, arising from the natural passage of time and genetics of the body. Or it may be extrinsic, due to environmental factors interacting with the skin and many of these factors are related to the production of free radicals, such as smoking, excessive consumption of alcohol and stress, in this context, one of the assets that draw our attention in combating skin aging is resveratrol. Resveratrol is a phenolic compound found in various plants and foods, such as peanut, grape, and its derivatives. This compound carries a variety of biological activities such as antioxidants, anti-inflammatory, cardioprotective, chemopreventive, and neuroprotective. The present article is characterized as being a descriptive bibliographical research with a qualitative approach and aims to carry out an updated bibliographic review on resveratrol and its use in the prevention of cutaneous aging. It is concluded that resveratrol has an antioxidant action and is an activator of sirtuin 1, which in turn activates DNA repair proteins, which may be useful in anti-aging treatment.

Keywords: skin aging; free radicals; rejuvenation; resveratrol; sirtuin 1.

\section{RESUMO}

A melhora dos parâmetros de saúde da população é um dos maiores feitos da humanidade e essa conquista se transformou em um desafio para os tempos de hoje. Viver mais é importante, desde que possamos adicionar qualidade de vida, física e mental, para os anos que ganhamos, e por isso a busca por recursos que possam nos ajudam a atingir esse objetivo tem estimulado novas pesquisas e dentre essas, destaca-se a 
procura de ativos a serem utilizados em formulações cosméticas, que possam combater o envelhecimento cutâneo. O envelhecimento da pele pode ser intrínseco, ou seja, aquele decorrente da passagem natural do tempo e da genética do corpo, ou pode ser extrínseco, aquele provocado por fatores ambientais, que interagem com a pele, e muitos desses fatores estão relacionados à produção de radicais livres, como tabagismo, consumo exagerado de álcool e estresse e, nesse contexto, um dos ativos que nos chama a atenção, no combate ao envelhecimento cutâneo, é o resveratrol. O resveratrol é um composto fenólico, encontrado em várias plantas e alimentos como o amendoim, uva e seus derivados, que exerce uma variedade de atividades biológicas como antioxidantes, anti-inflamatórias, cardioprotetoras, quimiopreventivas e neuroprotetoras. O presente artigo é caracterizado como sendo uma pesquisa bibliográfica do tipo descritiva com abordagem qualitativa e que tem como objetivo realizar uma revisão bibliográfica atualizada sobre o resveratrol e seu uso na prevenção do envelhecimento cutâneo. O resveratrol tem ação antioxidante e é ativador da sirtuína 1, que por sua vez, ativa proteínas reparadoras do DNA, podendo assim ser auxiliar no tratamento antienvelhecimento.

Palavras-chave: envelhecimento cutâneo; radicais livres; rejuvenescimento; resveratrol; sirtuína 1.

\section{INTRODUÇÃO}

O número de idosos ( $\geq 60$ anos de idade) no Brasil, passou de 3 milhões em 1960, para 7 mi1hões em 1975 e 14 milhões em 2002 (aumento de $400 \%$ em 40 anos), e deverá alcançar 32 milhões em 2020 (1). Porém, a forma como se envelhece tem preocupado muitas pessoas, pois já não basta viver mais, é necessário viver com qualidade de vida, física e mental. Assim, a busca por meios e, mais especificamente, substâncias que favoreçam esse envelhecimento saudável tem impulsionado novas pesquisas (2). Além de haver preocupações em relação à saúde física e ao bem-estar, existe também a preocupação com o envelhecimento cutâneo, pois cada vez mais a população deseja envelhecer sem apresentar as marcas dos anos vividos, e busca por métodos de intervenção para retardar ao máximo as marcas de envelhecimento (3)

O envelhecimento é um processo que traz alterações sobre todas as estruturas e órgãos do corpo; entretanto, a pele, mais especificamente da região facial, é a primeira a demonstrar os sinais do envelhecimento, que podem ser observados por meio das linhas de expressão, da flacidez cutânea, das manchas senis, entre outras características. Esse conjunto de alterações estimula os indivíduos a procurarem por procedimentos estéticos chamados de rejuvenescedores (4).
Dentre as substâncias cosméticas rejuvenescedoras, ou seja, utilizadas para a prevenção e tratamento do envelhecimento cutâneo, o resveratrol pode ser destacado, que está presente em diversas fontes como no eucalipto, no amendoim, na amora e, em especial, em uvas e seus derivados (5).

O resveratrol exerce diversas atividades biológicas, dentre as quais cardioprotetora e neuroprotetora; o combate ao envelhecimento e ao câncer, devido à suas propriedades antioxidantes, evitando desta forma, a oxidação proteica das células decorrente do ataque de espécies reativas de oxigênio, resultantes do metabolismo mitocondrial celular (6); além de proteger as células contra danos oxidativos associados aos efeitos dos radicais livre e radiação UV na pele, retardando o fotoenvelhecimento (7). Por essa razão, o resveratrol tem sido cada vez mais utilizado em produtos cosméticos.

Dessa forma, o objetivo do presente trabalho foi realizar uma revisão bibliográfica atualizada sobre o resveratrol e seu uso na prevenção do envelhecimento cutâneo.

\section{MÉTODO}

Trata-se de uma revisão bibliográfica exploratória-descritiva com abordagem qualitativa. Para atender o objetivo do estudo, as produções científi- 
cas referentes ao tema foram pesquisadas em livros e nos bancos de dados das bibliotecas eletrônicas Bireme, LILACS, SciELO, Pubmed e Periódicos CAPES, no período de 1999 a 2019. Os descritores utilizados para a seleção foram: envelhecimento, envelhecimento cutâneo; radicais livres, rejuvenescimento e resveratrol.

As estratégias utilizadas para inclusão dos artigos neste estudo foram artigos de pesquisas com estudos in vivo e in vitro, de revisão e artigos publicados nas versões inglês, espanhol e português, disponíveis por completo nas bases eletrônicas. Os critérios de exclusão utilizados foram artigos repetidos, artigos incompletos e artigos e que não representavam a temática.

\section{RESULTADOS E DISCUSSÃO}

Caracterizado como um processo progressivo e inevitável, o envelhecimento é considerado um conjunto de alterações morfológicas, fisiológicas e bioquímicas inevitáveis que ocorrem progressi- vamente no organismo (4), sendo que, de todos os órgãos e sistemas, a pele é o que sofre mais com este processo.

Os resultados do envelhecimento cutâneo são quase imperceptíveis antes dos 40 anos, pois a maioria das mudanças decorrentes da idade ocorrem nas proteínas da derme. Uma destas proteínas é o colágeno, que diminui quantitativamente, se enrijece e se quebra, tornando-se desorganizando e formando um emaranhado amorfo, assim como os fibroblastos, que são responsáveis por produzirem fibras elásticas, resultando em uma pele com sulcos e rugas. Durante esse processo também ocorre uma diminuição na capacidade de retenção hídrica e menor capacidade funcional das glândulas sudoríparas e sebáceas, deixando a pele com aspecto ressecado $(8,9)$.

Com base nos sinais apresentados pela pele envelhecida foi desenvolvida a Classificação de Glogau (Tabela 1), que divide o envelhecimento cutâneo em quatro graus. Com o passar do tempo, esta tornou-se uma ferramenta auxiliar para que profissionais possam escolher produtos e tratamen-

Tabela 1. Classificação de Glogau e os quatro graus de envelhecimento cutâneo, de acordo com os sinais que a pele apresenta.

\begin{tabular}{|c|c|c|}
\hline Classificação & Características & $\begin{array}{l}\text { Idade/anos } \\
\text { (Aproximada) }\end{array}$ \\
\hline $\begin{array}{l}\text { Grau I } \\
\text { Fotoenvelhecimento Suave }\end{array}$ & $\begin{array}{l}\text { - Poucas linhas de expressão (em grande parte dinâmicas) } \\
\text { o Poucas alterações pigmentares } \\
\text { o Ausência de queratoses } \\
\text { o Poucas sequelas acneicas }\end{array}$ & $20-30$ \\
\hline $\begin{array}{l}\text { Grau II } \\
\text { Fotoenvelhecimento Moderado }\end{array}$ & $\begin{array}{l}\text { - Rugosidades evidentes (linhas nasolabial e ao redor dos olhos) } \\
\text { o Manchas senis precoces } \\
\text { o Queratoses palpáveis (mas não visíveis) } \\
\text { o Lentigos senis visíveis } \\
\text { o Discretas lesões acneicas }\end{array}$ & $30-40$ \\
\hline $\begin{array}{l}\text { Grau III } \\
\text { Fotoenvelhecimento Avançado }\end{array}$ & $\begin{array}{l}\text { - Rugosidade estática e dinâmica } \\
\text { - Discromias muito evidentes } \\
\text { - Queratoses visíveis } \\
\text { - Cicatrizes de acne } \\
\text { - Telangiectasias }\end{array}$ & $50-60$ \\
\hline $\begin{array}{l}\text { Grau IV } \\
\text { Fotoenvelhecimento Severo }\end{array}$ & $\begin{array}{l}\text { - Rugosidade estática e dinâmica disseminadas } \\
\text { o Discromias muito evidentes (pode haver pele amarelo-cinzentada } \\
\text { e lesões malignas) } \\
\text { o Queratoses actínicas } \\
\text { o Cicatrizes de acne }\end{array}$ & $\begin{array}{l}60-70 \\
\text { (ou mais) }\end{array}$ \\
\hline
\end{tabular}

Matos (2014) (10). 
tos mais adequados para alcançar os melhores resultados com cada cliente (10).

Existem diversas teorias que tentam justificar o processo de envelhecimento e quais seriam os fatores desencadeantes, como os defeitos genéticos e o surgimento de doenças (11), ou os fatores externos como a toxicidade do meio ambiente, a exposição crônica e cumulativa dos raios ultravioleta, o tabagismo, o álcool, o estresse e a poluição do $\operatorname{ar}(12)$.

Visto que o envelhecimento é um processo multifatorial, existem várias teorias, porém, a mais aceita é a teoria dos radicais livres (13). Essas espécies químicas participam de processos que originam reações químicas, como a oxidação (14), que resultam no estresse oxidativo das células, um processo que causa dano tecidual e produzem compostos tóxicos ou danosos aos tecidos. É correto afirmar que um organismo se encontra sob esse estado quando existe um desequilíbrio entre os sistemas pró-oxidantes e antioxidantes, de maneira que os primeiros sejam predominantes (15).

Conforme a idade progride, há uma diminuição do sistema antioxidante natural, quando comparado com um organismo jovem e o estresse oxidativo leva ao acúmulo de proteínas, carboidratos, lipídeos e DNA oxidados resultando no envelhecimento (16).

Classificação do envelhecimento cutâneo. $\mathrm{O}$ envelhecimento cutâneo pode ser dividido em envelhecimento cronológico ou intrínseco e envelhecimento extrínseco (17-18):

- Envelhecimento intrínseco ou biológico: relaciona-se diretamente com o avanço da idade, estando associado a genética e não está sujeito a fatores ambientais modificantes, como radiação UV.

- Envelhecimento extrínseco: relaciona-se aos fatores ambientais e é resultado de uma exposição acumulativa às fontes que influenciam a produção de radicais livres, que danificam as estruturas celulares, como as proteínas, lipídeos, DNA e estimulam o estresse oxidativo, impedindo que as células mantenham sua integridade e suas funções preservadas.
Cosméticos rejuvenecedores. A busca por novos compostos para prevenir ou atenuar o processo de envelhecimento é constante $(4,13)$, e vislumbrando esse cenário, a industria cosmética investe na pesquisa e desenvolvimento de novos ativos cosméticos ou novas formas de veiculação destes ativos (19-21).

Uma boa formulação cosmética rejuvenecedora deve atuar em diferentes linhas, auxiliando a diminuir os radiacais livres, hidratando a camada córnea, clareando as machas senis e, principalmente, melhorando o metabolismo dérmico e epidérmico, com o objetivo de atenuar as rugas e marcas de espressão $(4,10)$. Entre os inúmeros ativos rejuvenecedores disponíveis no mercado, o foco deste estudo foi o resveratrol.

Este composto foi isolado pela primeira vez das raízes de Veratrum grandiflorum (Maxim. ex Miq.) O.Loes (Melanthiaceae), por Michio Takaoka, em 1940 (22), e a partir daí o interesse por este composto se intensificou, pois, foi constatado que compostos fenólicos, como é o caso do resveratrol, exibem propriedades de remoção de radicais livres, ou seja, propriedades antioxidantes.

Para esse interesse, pode ter havido a contribuição do chamado "Paradoxo Francês", criado por epidemiologistas franceses, que observaram uma baixa mortalidade devido a uma série de doenças, normalmente relacionadas ao avanço da idade do paciente, apesar dos altos níveis de gordura saturada na dieta e tabagismo. Foi presumido que a ingesta moderada de vinho tinto por um longo período seria benéfica para a saúde (23).

Entretanto, o mesmo estudo destacou que é difícil estimar a ingestão média de alimentos contendo resveratrol, considerando que a concentração desse composto é altamente variável. Além disso, e de acordo com os pesquisadores, pode não ser possível ingerir uma quantidade suficiente de resveratrol diariamente, pois a quantidade da ingesta desses alimentos teria que ser muito grande (23). Sautter e cols (2005) corroboraram com esta afirmação, e destacaram que as amostras de vinho Pinot Noir francês avaliadas, apresentavam uma variação na concentração de resveratrol entre 0,361 e 1,972 $\mathrm{mg} / \mathrm{L}$ e nos sucos de uva, elaborados no Brasil, a concentração relatada foi de 0,19 a $0,90 \mathrm{mg} / \mathrm{L}$ (5). 
Embora não tenha sido encontrado qualquer artigo que citasse precisamente a dosagem oral diária recomendada de resveratrol, suplementos comercializados no mercado, utilizam usualmente, doses entre $100 \mathrm{mg}$ a $250 \mathrm{mg}$.

Muitos estudos ainda estão em andamento para obter dados mais específicos sobre a dosagem oral adequada de resveratrol, bem como para estudar derivados desse composto, como o SRT501, uma versão micronizada do resveratrol, que pode ter maior percentual de aproveitamento pelo organismo (24).

Vitaglione e cols (2005) contestaram o efeito protetor de doenças coronárias pelo resveratrol, observado pelo Paradoxo Francês. Segundo eles, o benefício trazido pelo vinho pode se dar pela ingestão dos vários outros polifenois encontrados nessa bebida e não apenas como resultado do resveratrol isoladamente (25).

As plantas sintetizam uma ampla variedade de compostos químicos importantes para atender a uma variedade de funções ecológicas, que não apenas aumentam sua capacidade de sobrevivência, mas também podem ser responsáveis por uma série de efeitos benéficos relacionados à sua saúde (2). Um destes compostos químicos é o resveratrol, que é caracterizado como uma fitoalexina, pois ele é produzido pelas plantas como mecanismo de defesa contra condições desfavoráveis, como fungos, bactérias e radiação ultravioleta, por exemplo (26).

A fórmula molecular do resveratrol é $\mathrm{C}_{14} \mathrm{H}_{12} \mathrm{O}_{2}$ e sua estrutura básica consiste em dois anéis fenólicos ligados por uma dupla ligação de estireno, que forma o 3,5,4'-tri-hidroxiestilbeno, essa dupla ligação é a responsável pelas formas isométricas cis e trans do resveratrol, (22).

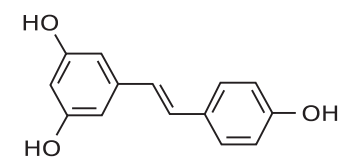

Trans-Resveratrol

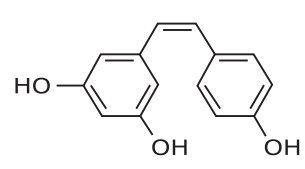

Cis-Resveratrol
O isômero trans-resveratrol (trans-3,5,4'trihidroxiestilbeno) é convertido em cis-resveratrol (cis-3,5,4'-trihidroxiestilbeno) na presença de luz visível, altas temperaturas e baixo $\mathrm{pH}$ (27).
A forma mais estável é o trans-resveratrol e isso faz com que seja considerado sua forma mais ativa no organismo $(5,28)$. Os suplementos e soluções que contenham resveratrol em sua composição devem ter seus parâmetros de oxigênio e radiação ultravioleta controlados durante os processos de produção, acondicionamento e conservação do mesmo (34).

No organismo humano, o resveratrol é rapidamente absorvido no intestino e, devido à sua lipofilia, poderia ser inferida uma maior absorção, e consequentemente, maior biodisponibilidade desse composto quando associado a uma dieta rica em lipídeos (34). Porém, em um estudo realizado por Vitaglione e cols (2005), verificou-se que a biodisponibilidade do trans-resveratrol, proveniente do vinho tinto, não depende da quantidade lipídica da refeição e nem do tipo de lipídio ingerido (25).

Segundo os estudos farmacocinéticos por Alves e cols. (2015), a ingesta de resveratrol pela manhã conduz a uma maior biodisponibilidade do composto e, após sua biotransformação, ele é eliminado de 70 a $98 \%$ pela urina ou fezes em 24 horas (34).

Visto que o resveratrol é metabolizado no fígado, e boa parte dele excretado pelo sistema urinário, pessoas que tenham esses sistemas em funcionamento comprometido ou que se encontrem sob medicação que os afete, poderão responder de forma diferente de pessoas saudáveis ao uso oral do resveratrol (34).

A fim de resolver o problema da baixa biodisponibilidade do resveratrol, assim como de seu perfil farmacocinético complicado, é necessário o desenvolvimento de sistemas específicos de fornecimento controlado e dirigido de medicamentos, por isso, técnicas como micropartículas, nanopartículas, microesferas, microencapsulação e nanoencapsulação têm recebido grande atenção dos pesquisadores (27).

Propriedades do Resveratrol. A compreensão de como o resveratrol exerce seus efeitos é importante, não apenas para a percepção potencial das causas biológicas das doenças relacionadas à idade, mas também para permitir o desenvolvimento de moléculas mais potentes e específicas (29). Nesse contexto, vários fatores podem interferir no mecanismo de ação do resveratrol em nosso organismo, como as condições das células, a concentração de 
resveratrol utilizada e de sua duração de contato, bem como a reação redox citosólica (2), ou seja, as reações de redução e oxidação dentro do citoplasma da célula.

Ruivo e cols (2015) afirmaram que dependendo desses fatores, o resveratrol pode apresentar duplicidade em seu mecanismo de ação, podendo atuar protegendo a célula ou participando de sua apoptose pois, a estrutura química desse composto permite sua interação com vários receptores, como quinase e outras enzimas, e por causa disso, pode prevenir doenças que são consequência de dano ou morte celular desencadeadas por estresse oxidativo, tais como Alzheimer, Parkinson, cânceres, doenças cardíacas, esclerose múltipla (2). Além disso, também possui características neuroprotetora, quimioprotetora, antidiabetes, anti-inflamatória e antioxidante $(28,30,31)$.

Resveratrol e a sirtuína 1 (SIRT1). Um dos mecanismos responsáveis pelos possíveis efeitos da longevidade do organismo ocasionados pelo resveratrol ocorre por meio de sirtuínas. As sirtuínas são proteínas que tem participação na ativação de proteínas celulares relacionadas ao reparo do DNA (32). A SIRT1 pode regular funções celulares como apoptose, biogênese mitocondrial, inflamação, metabolismo de glicose e lipídios, autofagia e adaptações ao estresse celular (30), pois, regula as respostas celulares aos agentes que danificam o DNA (33).

Em 2003 foi realizada uma triagem para pequenas moléculas ativadoras da SIRT1 na qual foram identificadas 21 moléculas diferentes, sendo que o resveratrol foi dado como a mais potente delas (29).

North e Verdin (2004) afirmaram que a regulação das sirtuínas pelos polifenois, nos dá uma ligação entre os efeitos dos produtos vegetais, como no caso de produtos contendo resveratrol em sua composição, na saúde, longevidade e no envelhecimento do organismo como um todo (33).

Administração tópica do resveratrol. Segundo Berman e cols. (2017), do ponto de vista farmacocinético, o resveratrol provou ser mais efetivo quando aplicado topicamente do que quando administrado oralmente, justamente por ser rapidamente metabolizado e excretado (24).
Entre os carreadores nanoestruturados com potencial aplicação tópica, podem ser destacadas as nanopartículas lipídicas sólidas e as nanoemulsões, além das microemulsões. Esses sistemas carreadores são constituídos por lipídios altamente purificados e por misturas complexas de glicerídeos, além disso, possuem excelente estabilidade física, capacidade de proteção de fármacos instáveis, capacidade de controle da liberação, ótima tolerabilidade e possibilidade de vetorização, ou seja, possiblidade de transporte do fármaco diretamente do tecido onde foi administrado até seu local de ação. Desses três tipos de carreadores lipídicos, as microemulsões tem uma maior capacidade de incorporação do resveratrol (35).

Resveratrol em cosméticos. Os compostos antioxidantes, como o resveratrol, possuem notoriedade em formulações cosméticas por serem muito benéficos contra a produção de radicais livres. Estes possuem como função primária a de reduzir a velocidade de iniciação e/ou propagação dos processos oxidativos, minimizando os danos às moléculas e estruturas celulares (36).

Nesse contexto, a comunidade científica tem demonstrado que formulações com resveratrol podem estimular a proliferação dos fibroblastos, devido sua propriedade antioxidante, que protege as células contra os danos causados pelos radicais livres, além de apresentar afinidade pelos receptores de proteína estrogênica, que estão localizados em fibroblastos e macrófagos e participam da estimulação da produção de colágeno tipo I e II. Desta forma o resveratrol, por estimular esses receptores, contribui para a estimulação da produção de colágeno tipos I e II (7).

Estudos sobre o uso do resveratrol em cosméticos foram realizados por Katiyar (2003) e Afaq e Mukhtar (2006), que demonstraram que o resveratrol atua reduzindo os níveis de espécies reativas de oxigênio, nos queratonócitos expostos a UVA e apontaram que algumas alterações ultraestruturais celulares podem ser prevenidas $(37,38)$. Além disso, o resveratrol na pele também exerce seu efeito protetor sobre as células epidérmicas, ligando-se a locais específicos de ligação ao polifenol. Mecanismos intracelulares subjacentes ao efeito protetor do resveratrol não são apenas devido às suas 
atividades antioxidantes, mas também envolvem sua ação inibitória na apoptose (39).

Após o estresse oxidativo, os queratinócitos liberam interleucina-1 (IL-1) e o fator de necrose tumoral alfa (TNF- $\alpha$ ), que levam à ativação de MAPK quinases, que por sua vez estimulam a síntese do fator de transcrição da proteína ativadora-1 (AP-1) e ativam o fator fator nuclear $\mathrm{kB}(\mathrm{NF}-\kappa \mathrm{B})$. Esses eventos resultam na indução da atividade da metaloproteinase da matriz, levando à interferência nas vias de sinalização intracelular, responsáveis pela expressão de genes que regulam o processo de síntese de colágeno nos fibroblastos. Como resultado desse processo, as lesões fibrilares da pele são prejudicadas pela degradação do colágeno tipo I e III e pela hipertrofia e degradação da elastina e ácido hialurônico. Neste contexto, o mecanismo de atividade protetora do resveratrol está relacionado à sua capacidade de neutralizar a formação de radicais livres e espécies reativas de oxigênio e impedir processos de oxidação lipídica (39).

Resveratrol $x$ envelhecimento cutâneo. Embora haja um debate persistente sobre a definição de antienvelhecimento, para os fatores que contribuem com o envelhecimento existe mais consenso, e dentre estes fatores, a teoria dos radicais livres ganhou aceitação considerável entre a comunidade acadêmica (40).

Nessa perspectiva, entre uma das possíveis soluções para esse problema estaria o uso de antioxidantes nas formulações cosméticas e sendo assim, embasado na pesquisa feita, as propriedades biológicas do resveratrol fazem dele um ótimo candidato à agente antienvelhecimento em cosméticos.

Em seu trabalho, Alves e cols. (2015) destacaram a utilização tópica do resveratrol, ressaltando sua propriedade antioxidante, que auxilia no combate às agressões externas como poluição e fumo, sendo este dezessete vezes mais potente que a idebenona (34). Batista e cols (2019) corroboraram com essa informação e destacaram que o composto é capaz de ativar a proteína sirtuína 1 , sendo esta responsável pela ativação de outras proteínas responsáveis por reparos a danos, ocasionados pelos radicais livres, no DNA celular (32).

Stojanović e cols. (2001) também encontraram estes resultados e destacaram que o resveratrol é um eficiente antioxidante, mostrando ser $95 \%$ eficiente nesse quesito, enquanto a vitamina $\mathrm{E}$ obteve $65 \%$ de eficiência e a vitamina $\mathrm{C}$ apenas $37 \%$. Esses resultados foram obtidos em um estudo clínico, com duração de 12 semanas e contando com 55 participantes (idade entre 40 e 60 anos). Os autores relataram que houve um aumento na expressão da heme-oxigenase-1, o que protegeu as células contra os danos causado pelos radicais livres. A expressão da heme-oxigenase-1, ativa o fator de transcrição Nrf2 (nuclear factor erythroid 2-related factor 2), que se liga ao elemento de resposta antioxidante (ARE) e codifica duas enzimas: glutationa S-transferase e NAD (P) H: quinona oxidoredutase 1 (NQO1). A ativação de Nrf2 e ARE é um passo importante no processo de resposta antioxidante da célula. Isso possibilita a expressão de genes que codificam proteínas citoprotetoras, que neutralizam os metabólitos eletrofílicos produzidos pela transformação de xenobióticos, radicais livres e espécies reativas de oxigênio e estabilizam o potencial oxidativo celular. (41).

Na comparação do resveratrol com seus derivados sintéticos, Baxter (2008) afirmou que sua forma nativa é mais potente na capacidade de absorção de radicais livres, do que as vitaminas antioxidantes e seus derivados atualmente utilizados no mercado (40).

Lalastra e Villegas (2007) também mostraram resultados positivos em relação ao resveratrol, uma vez que confirmaram que o resveratrol tem mostrado prolongar a vida útil de várias espécies, implicando assim em seu potencial como agente antienvelhecimento (42). Além disso, os efeitos resultantes do resveratrol nos experimentos demonstrados por Pandey e Rizvi (2010) comprovaram as evidências existentes em relação a sua propriedade antioxidante (6).

O estudo realizado por Fehér e cols. (2007) corroborou esses resultados, destacando como tratamento e prevenção de algumas doenças dermatológicas, sobretudo relacionadas ao envelhecimento cutâneo. O tratamento contendo polifenois do vinho, em especial o resveratrol, pode se mostrar benéfico devido ao seu efeito de eliminação de radicais livres (43). Nesse contexto, Lima e cols. (2018) apontaram que no mercado da estética, 
a técnica de vinhoterapia tem ganhado espaço, pois pode ser utilizada de diversas maneiras como em bandagens, banhos de imersão, massagens relaxantes, esfoliação entre outros (44).

\section{CONCLUSÃO}

O envelhecimento cutâneo é um processo inevitável, mas que pode ser retardado. Existe uma grande demanda por produtos e tratamentos que previnam o envelhecimento precoce e seus sinais, que são causados por múltiplos fatores como exposição solar, estresse, tabagismo, álcool e poluição do ar. Com esse incentivo, muitas marcas dermocosméticas desenvolvem e apresentam linhas com propriedade antioxidantes, com o intuito de atenuar os efeitos do envelhecimento como as rugas, a flacidez e a secura cutânea.

\section{REFERÊNCIAS}

1. Veras RP, Oliveira M. Envelhecer no Brasil: a construção de um modelo de cuidado. Ciênc. Saúde Coletiva. 2018;23(6):1929-1936. DOI: 10.1590/141381232018236.04722018.

2. Ruivo J, Franciso C, Oliveira R, Figueiras A. The main potentialities of resveratrol for drug delivery systems. Braz. J. Pharm. Sci. 2015.51(3):499-513. DOI: 10.1590/ s1984-82502015000300002.

3. Deccache DS, Santos EP, Souza VP. Formulação dermocosmética contendo DMAE glicolato e filtros solares: desenvolvimento de metodologia analítica, estudo de estabilidade e ensaio de biometria cutânea. [Dissertação]. Rio de Janeiro: Programa de Pósgraduação em Ciências Farmacêuticas, Universidade Federal do Rio de Janeiro. 2006.

4. Ribeiro CJ. Cosmetologia aplicada a Dermoestética. 1nd. ed. São Paulo: Pharmabook. 2006.

5. Sautter CK, Denardin S, Alves AO, Mallmann CO, Penna NG, Hecktheuer LH. Determinação de resveratrol em sucos de uva no Brasil. Ciênc. Tecnol. Aliment. 2005;25(3):437-442. DOI: 10.1590/S0101-2061200500 0300008 .

6. Pandey KB, Rizvi SI. Resveratrol may protect plasma proteins from oxidation under conditions of oxidative stress in vitro. J. Braz. Chem. Soc. 2010;21(5):909-913. DOI: $10.1590 / \mathrm{s} 0103-50532010000500020$.
O avanço da pesquisa científica possibilitou a introdução do resveratrol no mercado de beleza e estética, um composto fenólico muito encontrado nas uvas, cuja ação protege as células da oxidação por radicais livres, controla o estresse oxidativo das células e ativa a sirtuína-1, sendo essa responsável pela ativação de proteínas responsáveis por reparos no DNA, contribuindo para a saúde e longevidade do organismo como um todo, sendo assim reconhece-se que o resveratrol, ingerido ou aplicado topicamente, pode ser utilizado de forma satisfatória no combate ao envelhecimento cutâneo.

Questões como biodisponibilidade, metabolismo e dosagem do resveratrol ainda permanecem em grande parte sem reposta definitiva. Além disso, os benefícios da suplementação oral de resveratrol continuam a ser especulativos na pendência de relatos de ensaios clínicos com humanos em condições específicas. Com isso, ainda há muito a ser estudado quanto ao resveratrol.

7. Ratz-Łyko A, Arct J. Resveratrol as an active ingredient for cosmetic and dermatological applications: a review. J. Cosmet. Laser. Ther. 2018;21(2):84-90. DOI: 10.1080/ 14764172.2018 .1469767$.

8. Strutzel E, Strutzel E, Cabello H, Queiroz L, Falcão MC. Análise dos fatores de risco para o envelhecimento da pele: aspectos gerais e nutricionais. Rev. Bras. Nutr. Clin. 2007;22(2):139-145.

9. Tortora GJ, Derrickson B. Corpo humano fundamentos de anatomia e fisiologia. 10nd. ed. Porto Alegre: Editora Artmed. 2017.

10. Matos SP. Cosmetologia Aplicada. São Paulo: Érica. 2014.

11. Harris MMII, Nogueira NCC. Pele - estruturas, propriedades e envelhecimento. 3nd. ed. São Paulo: Editora Senac. 2009.

12. Pujol AP. Nutrição aplicada à estética. 1nd. ed. Rio de Janeiro: Editora Rubio Ltda. 2011.

13. Machado K.E. Vitamina $C$ na prevenção do envelhecimento cutâneo. Cosmetic. Toilet. 2016;28: 76-81.

14. Farinatti PTV. Teorias biológicas do envelhecimento: do genético ao estocástico. Rev. Bras. Méd. Esporte. 2002;8(4):129-138. 
15. Schneider CD, Oliveira AR. Radicais livres de oxigênio e exercício: mecanismos de formação e adaptação ao treinamento físico. Rev. Bras. Med. Esporte. 2004;10(4): 314-318. DOI: 10.1590/S1517-869220040 00400008.

16. Silva M, Wallison J, Ferrari B, Kusano C. Metabolismo Mitocondrial, Radicais Livres e Envelhecimento. Rev. Bras. Geriatr. Gerontol. 2011;14(3):441-451.

17. Alves R, Castro Esteves T, Trelles MA. Factores intrínsecos y extrínsecos implicados en el envejecimiento cutáneo Intrinsic and extrinsec factors related to cutaneous aging. Cir.plást. iberolatinoam. 2013;39(1):89-102.

18. Kede MPV, Sabatovich O. Dermatologia Estética. 3nd. ed. São Paulo: Atheneu, 2015.

19. Ruiz MA, Charles B, Morales ME, Gallardo V. Evaluation of the anti-wrinkle efficacy formulations with an anti-aging peptide (Argireline () ). Ars. Pharm. 2010;50(4):168-176.

20. Sheraz M, Ahmed S, Ahmad I, Shaikh RH, Vaid FHM, Iqbal K. Formulation and stability of ascorbic acid in topical preparations. Syst Rev. Pharma. 2011;2(2):86-90.

21. Telang P. Vitamin C in dermatology. Indian Dermatol Online J. 2013;4(2):143-146. DOI: 10.4103/2229- 5178. 110593.

22. Gambini J, Inglés $\mathrm{M}$, Olaso $\mathrm{G}$, Lopez-Grueso $\mathrm{R}$, Bonet-Costa V, Gimeno-Mallench L, Mas-Bargues C, Abdelaziz K, Gomez-Cabrera M, Vina J. Properties of resveratrol: in vitro and in vivo studies about metabolism, bioavailability, and biological effects in animal models and humans. Oxid Med Cell Longev. 2015;2015:1-13. DOI: $10.1155 / 2015 / 837042$.

23. Weiskirchen S, Weiskirchen R. Resveratrol: How Much Wine Do You Have to Drink to Stay Healthy?. Adv Nut. 2016;7(4):706-718. DOI: 10.3945/an.115.011627.

24. Berman AY, Motechin RA, Wiesenfeld MY, Holz MK. The therapeutic potential of resveratrol: a review of clinical trials. NPJ Precis. Oncol. 2017;35(1):1-35. DOI: 10.1038/s41698-017-0038-6.

25. Vitaglione P, Sforza S, Galaverna G, Ghidini C, Caporaso N, Vescovi PP, Fogliano V, Marchelli R. Bioavailability oftrans-resveratrol from red wine in humans. Mol Nutr Food Res. 2005;49(5):495-504. DOI: 10.1002/ mnfr.200500002.

26. Viola AMC, Cavadas CMG. Resveratrol: do laboratório à clínica. [Monografia]. Coimbra: Faculdade de farmácia, Universidade de Coimbra. 2016.

27. Perrone D, Fuggetta MP, Ardito F, Cottarelli A, De Filippis A, Ravagnan G, De Maria S, Lo Muzio L. Resveratrol (3,5,4'-trihydroxystilbene) and its properties in oral diseases. Exp. Ther. Med. 2017;14(1):3-9. DOI:10.3892/etm.2017.4472.
28. Santin NC, Caliari V. Resveratrol em uvas e vinhos e suas principais propriedades biológicas. Infarma. 2007;5(8):131:133.

29. Price NL, Gomes AP, Ling AJ, Duarte FV, MartinMontalvo A, North BJ, Agarwal B, Ye L, Ramadori G, Teodoro JS, Hubbard BP, Varela AT, Davis JG, Varamini B, Hafner A, Moaddel R, Rolo AP, Coppari R, Palmeira CM, De Cabo R, Baur JA, Sinclair DA. SIRT1 is required for AMPK activation and the beneficial effects of resveratrol on mitochondrial function. Cell. Metab. 2012;15:675-90. DOI: 10.1016/j.cmet.2012.04.003

30. Albertoni G, Schor N. Resveratrol plays important role in protective mechanisms in renal disease - mini-review. J. Bras. Nefrol. 2015;37(1):106-114. DOI: 10.5935/ 0101-2800.20150015.

31. Martins PP, Nicoletti MA. Polifenóis no vinho: resveratrol e seus benefícios. Infarma - Cienc Farmac 2016;28(4):216-225. DOI:10.14450/2318-9312

32. Batista MEV, Silva JPP, Rocha ICA, Lucena TL, Silva-Junior AHP. Papel do biólogo das sirtuínas no processo de envelhecimento humano: mini-revisão. Congresso Internacional de Envelhecimento Cutâneo. 2019. Disponível em: <http://www.editorarealize.com. br/revistas/cieh/trabalhos/TRABALHO_EV075_MD4 SA15_ID799_10092017154806.pdf >. Acessado em: $1 \overline{5}$ maio 2019.

33. North BJ, Verdin E. Sirtuins: Sir2-related NADdependent protein deacetylases. Genome Biol. 2004; 5(5):224. DOI:10.1186/gb-2004-5-5-224.

34. Alves ACL, Reis CP, Fitas M. O resveratrol como molécula anti-envelhecimento. [Dissertação]. Lisboa: Mestrado em Ciências Farmacêuticas, Universidade Lusófona de Humanidades e Tecnologias. 2015.

35. Nemen D, Lemos-Senna E. Preparação e caracterização de suspensões coloidais de nanocarreadores lipídicos contendo resveratrol destinado à administração cutânea. Quím. Nova. 2011;34:408-413. DOI:10.1590/S0100-404 22011000300008.

36. Bianchi MLP, Antunes LMG. Radicais livres e os principais antioxidantes da dieta. Rev Nutr. 1999; 12(2):123-130.

37. Katiyar SK. Skin photoprotection by green tea: antioxidant and immunomodulatory effects. Curr Drug Targets Immune Endocr Metabol Disord. 2003; 3:234-242.

38. Afaq F, Mukhtar H. Botanical antioxidants in the prevention of photocarcinogenesis and photoaging. Exp Dermatol. 2006;15:678-84. DOI: 10.1111/j.16000625.2006.00466.x. 
39. Bastianetto S, Dumont Y, Duranton A, Vercauteren F, Breton L, Quirion R. Protective action of resveratrol in human skin: possible involvement of specific receptor binding sites. PLoS One. 2010;5(9):1-12. DOI: 10.1371/ journal.pone.0012935.

40. Baxter RA. Anti-aging properties of resveratrol: Review and Report of a potent new antioxidant skin care formulation. J Cosmet Dermatol. 2008;7:2-7. DOI: 10.1111/j.1473-2165.2008.00354.x.

41. Stojanović S, Sprinz H, Brede O. Efficiency and Mechanism of the Antioxidant Action of transResveratrol and Its Analogues in the Radical Liposome Oxidation. Arch Biochem. Biophys. 2001;391(1):79-89. DOI:10.1006/abbi.2001.2388.
42. Lalastra CA, Villegas I. Resveratrol as an antiinflammatory and anti-aging agent: Mechanisms and clinical implications. Biochem. Soc. Trans. 2007;35(5): 1156-1160. DOI:10.1042/BST0351156

43. Fehér J, Lengyel G, Lugasi A. The cultural history of wine - theoretical background to wine therapy. Open Medicine. 2007;2(4): 379-391. DOI:10.2478/s11536007-0048-9.

44. Lima AF, Santana ECJ, Moreira JAR. Atuação da vinhoterapia no retardo do envelhecimento cutâneo: revisão de literatura. Rev. Cient. Fho. 2018;6(2):1-8. 